\title{
4. Who pays for the network when trade is international?
}

\section{Leonardo Meeus with Tim Schittekatte}

In this chapter, we answer four questions. First, who pays for the network? Second, why did national network tariffs start to be harmonized? Third, why was there a move away from transit charges? And fourth, how to share network investment costs between countries?

\subsection{WHO PAYS FOR THE NETWORK?}

Electricity networks are important infrastructure like roads, railways and fibre networks. Such important infrastructure is typically paid for through a combination of general taxation and user tariffs. However, electricity networks in Europe are mostly paid for by network users through so-called network tariffs. In what follows, we introduce the two types of network tariffs: connection charges and access charges. ${ }^{1}$

First, connection charges. As the name indicates, these charges are for connection to the grid at the time of connecting and are typically one-off payments that in some cases can be spread over time. They are often labelled 'super-shallow', 'shallow' or 'deep' connection charges. Super-shallow means a very cheap or free connection. Shallow means you pay for the cable and other necessary equipment to connect you to the electricity network's local feeder. You are the only user of that piece of the network so the cost can easily be attributed to you. Deep means that you also pay for network reinforcements that might be needed deeper inside the network to accommodate the new connection at your location. Deep charges try to influence the location of new connections by signalling where the network can still host additional connections without reinforcement and where reinforcement would be needed. Shallow connection charges are the dominant model in Europe, but there are also a few countries with deep charges (five countries in 2018). Connection charges can also vary within a country for different voltage levels and/or different grid users. Consumers and producers are not necessarily treated in the same way.

Second, access charges. These charges are paid on a monthly or bi-annual basis. Network access charges are usually divided between transmission access charges and distribution access charges. Grid users contribute to the network cost of the voltage level that they are connected to and the voltage levels above them. This means that grid users connected to the highest transmission-level voltage only pay transmission charges for that level, while households connected to the lowest distribution-level voltage pay for all the network levels above them through both transmission and distribution access charges. The origin of this cascading principle is that electricity flows from the highest voltage all the way down to the lowest. Transmission access charges are also used to recover the costs of some of the services that are 
provided by transmission system operators (TSOs). The European Network of Transmission System Operators for Electricity (ENTSO-E) reports that on average in Europe in 2018, 59 per cent of transmission access charges covered infrastructure costs, 31 per cent system services and 10 per cent losses.

TSOs also collect congestion revenue, which can cover part of their costs and thus can reduce the need to collect money through network tariffs. This revenue results from explicit or implicit auctioning of transmission rights, as was discussed in Chapter 2. According to ENTSO-E data, on average $€ 2$ billion of congestion revenue a year was collected in the period 2011-2015. In Annex 4A.1, we provide an example of how this congestion revenue is calculated under implicit auctioning of transmission rights.

\subsection{WHY DID NATIONAL NETWORK TARIFFS START TO BE HARMONIZED?}

In this section, we first discuss the level of harmonization of transmission network tariffs and then introduce two open issues.

\subsubsection{The Harmonization of Transmission Network Tariffs}

For the moment, network tariffs have only been harmonized at the transmission level, and only access charges, not connection charges, are harmonized. Moreover, only the access charges that apply to generators have to a certain extent been harmonized (the so-called G-component), not those that apply to consumers (the C-component). Not all countries have a G-component, but those that do (15 countries in 2018) have to comply with the caps listed in Table 4.1. These caps apply to the total amount of money that is collected from producers divided by their total output per year. Connection charges, charges related to system services and losses are excluded from this calculation. These caps were introduced in Regulation (EU) No 838/2010. The development of guidelines around the harmonization of transmission tariffs was first described in Regulation (EC) No 1228/2003, which was part of the Second Energy Package.

The main argument for a G-component in transmission access charges is that it ensures that generators consider transportation costs in their decisions. Connection charges can guide generators to locate where it would be cheaper to transport what they produce. Access charges can also guide decisions to produce or consume in the period after the connection. When the network is in a critical condition, generators can be given a signal not to produce. The implementation of a geographically differentiated G-component is limited to the UK, Ireland and Sweden. The argument against a G-component is that generators in that country are at a competitive disadvantage with respect to generators that access the European electricity market via a country that does not have such a G-component. It is this distortion of the level playing field that motivated the introduction of the above-mentioned caps. Moreover, locational signals can be more effectively provided through variations in energy prices over well-defined zones (or nodes) as described in Chapter 3.

A similar logic can be applied to distribution network tariffs. Indeed, producers increasingly access the European electricity market through distribution grids. In our research, we made a first attempt to calculate the spillover effects caused by distribution tariffs and concluded that they can be significant. ${ }^{2}$ During the negotiations on the Clean Energy Package, the European 
Table 4.1 Maximum annual average transmission charges paid by producers according to Regulation (EU) No 838/2010

\begin{tabular}{ll}
\hline & $\begin{array}{l}\text { Maximum annual average transmission charge paid by } \\
\text { producers }\end{array}$ \\
\hline Great Britain, Ireland and Northern Ireland & $€ 2.5 / \mathrm{MWh}$ \\
Romania & $€ 2 / \mathrm{MWh}$ \\
Denmark, Finland and Sweden & $€ 1.2 / \mathrm{MWh}$ \\
All other EU countries & $€ 0.5 / \mathrm{MWh}$ \\
\hline
\end{tabular}

Commission proposed harmonizing distribution network tariffs through the EU network code process, but this proposal was dropped due to strong opposition on the part of stakeholders and national governments.

\subsubsection{Network Tariffs - Open Issues}

In this subsection we introduce two open issues related to network tariffs: the treatment of energy storage and the implementation of the cost-reflectivity principle. ${ }^{3}$

First, the treatment of energy storage. In some countries, energy storage is charged like generation and in other countries like consumption. There are also countries where energy storage is charged for consumption and for generation, and countries that have started to treat storage separately when it comes to network access charges. For instance, Belgium has exempted newly connected energy storage assets from transmission charges for ten years. Charges that apply to generators to access the European electricity market to create a level playing field have been harmonized so the same logic could be applied to energy storage. We expect energy storage to play an important role in the electricity system of the future, so we can expect that debate on this issue will continue.

Second, the implementation of the cost-reflectivity principle. Regulation (EU) 2019/943 mandates ACER to come up with best practice reports on transmission and distribution network tariffs. The regulation also states that these tariffs should become more cost-reflective, which can include locational and time-varying signals. Historically, distribution access charges were simple rather than cost-reflective. Consumers paid in proportion to the volume of their annual consumption in euro/kWh. With the emergence of rooftop photovoltaic (PV) panels, electric vehicles, heat pumps and home batteries, simple tariffs increasingly give distorted signals.

The best-known example is what happened with the large-scale introduction of rooftop PVs. Wealthy households used to consume more so they contributed more to distribution network costs. Today, volumetric tariffs achieve the opposite. Wealthy households can more easily invest in rooftop PVs. In some hours of the day, these households inject the output of their PV panels into the network, and in other hours they withdraw that energy back from the network. If we only measure and charge on the basis of the net effect, they no longer pay for the network they continue to use at the expense of other users who cannot afford PV panels.

Cost-reflective tariffs mean you pay for the costs you cause. This is easier said than done, and we also do not want tariffs to become too complicated. Cost-reflectivity can become politically sensitive if it implies different charges for urban and rural areas, or if it implies revisiting the allocation of network costs between households and industry. Following the 
cascading principle, households connected to distribution networks contribute to transmission network costs, while large industrial consumers connected to transmission networks do not contribute to distribution network costs, which could be challenged in an electricity system that is increasingly decentralizing.

\subsection{WHY WAS THERE A MOVE AWAY FROM TRANSIT CHARGES?}

In this section we first introduce transit charges and then discuss the inter-TSO compensation (ITC) scheme that replaced them. ${ }^{4}$

First, transit charges. Who pays for the network becomes more complicated when you introduce international trade. As discussed in the previous sections, national network tariffs mean charging producers and consumers connected to the transmission and distribution network when they connect or when they access the grid. However, what should be done with traders that use the network to transfer energy from one national network to another, possibly also crossing the networks of transit countries? Most countries introduced a so-called transit charge to apply to cross-border transactions. This meant that traders not only needed to buy transmission rights to be able to trade across borders, but they also had an extra transaction cost for trading across the border.

However, cross-border transactions only cause network costs to the extent that they cause flows. There are many more transactions than physical flows, and transactions can go both ways across a certain border so that they cancel out and do not cause any flow or cost. It is also possible to have physical flows across a network even if there are no transactions. Traders can transact via another path around a country while the flow will still go through its network. Transit charges also allowed countries to tax international trade in order to reduce their national network tariffs. Transit charges were an obstacle to trade as they were increasing transaction costs rather than charging the users of the grid. Therefore, they were finally abolished in 2014 .

The process that led to the abolishment of transit charges is interesting, as it played out over many years in the Florence Forum. Stakeholders started to meet informally in Florence and the gathering was then institutionalized by the European Commission. In 2002, the 8th Florence Forum agreed to abolish all existing transit charges while still allowing capped export charges. Initially the cap on export charges was set at $€ 1 / \mathrm{MWh}$, but was then reduced to $€ 0.5 / \mathrm{MWh}$. Finally, this led to their abolishment in 2004, long before roaming was abolished for mobile phones, which received much more attention.

Second, the inter-TSO compensation (ITC) scheme. In 2002, eight European TSOs signed a first ITC agreement. Through their associations (ETSO and later ENTSO-E), TSOs continued to develop and expand this mechanism. Under this scheme, TSOs from countries that cause international flows by importing or exporting contribute to a fund and TSOs from countries that host international flows receive money from that fund. TSOs that pay into the fund collect the money by increasing their national network tariffs and those that receive money from the fund use it to lower their national network tariffs. It is a zero-sum game that pays for the costs caused by transit flows and avoids the problems with transit charges on transactions.

Even though the principle of the ITC scheme is clear, its implementation has proven to be challenging. To determine the size of the fund, TSOs and their national regulatory authorities (NRAs) need to agree on the level of costs, and there are different cost-reporting practices. The 
definition of a transit has also been challenged. There can be transit flows that cross a country, but there can also be transit flows that enter a country to run along the border and exit again. Both would count equally as transits, but they do not cause the same level of costs. It therefore took a long time to agree on a definitive ITC methodology. Note that transit flow is a concept that is also used in the debate on flow-based market coupling (see Annex 3A.1 and Annex 3A.2 in Chapter 3), but the definition is not the same as in the debate on the ITC methodology. As with G-charges in the previous section, the ITC mechanism was already part of Regulation (EC) No 1228/2003 and it was further formalized in Regulation (EU) No 838/2010.

In other words, the ITC scheme is far from perfect but it did help to abolish transit charges, which were worse. Sensitivities related to transit charges and the ITC scheme dominated the debate for a long time, but gradually faded. In 2017, the ITC fund amounted to $€ 259.3$ million. This consisted of $€ 100$ million to compensate for infrastructure costs and $€ 159.3$ million to compensate for losses caused by transits. In comparison with the schemes we will discuss in the next section and that have received most of the attention in recent years, the money that circulates in the ITC mechanism is relatively small and not used to provide investment signals but instead to allocate sunk investments costs.

\subsection{HOW TO SHARE NETWORK INVESTMENT COSTS BETWEEN COUNTRIES?}

In this section we first introduce the process of prioritizing projects of common interest (PCI) in Europe and then discuss so-called cross-border cost allocation (CBCA) agreements for these projects, which determine how network investment costs are charged across countries.

First, projects of common interest (PCIs). Following Regulation (EC) No 714/2009, TSOs make national transmission investment plans and they are consolidated into the so-called Ten-Year Network Development Plan (TYNDP). ${ }^{5}$ The TYNDP is one of ENTSO-E's tasks, and in 2018 it argued that $€ 114$ billion of investment in power lines would be needed by 2030. Regulation (EU) No 347/2013, better known as the Trans-European Energy Networks (TEN-E) Regulation, then introduced a process in which some of these projects could become PCIs. The list of PCIs also includes third-party projects. Third-party projects can be merchant projects that have followed an exemption process or regulated projects from countries that allow third parties to compete with TSOs to develop such projects. The first PCI list was published in 2013. It is updated every two years and contains a selection of electricity transmission lines, gas and oil pipelines, gas and electricity storage projects, electricity smart grids, and carbon dioxide transport infrastructure. The total investment cost of the electricity projects on the 2017 PCI list is $€ 49.3$ billion - almost half of the TYNDP investment in 2018.

To obtain PCI status, projects need to conduct a cost-benefit analysis (CBA) following a methodology designed by ENTSO-E with supervision by ACER. They can then be ranked on the basis of their CBA and be selected in a process that is set out in the TEN-E Regulation. Projects with PCI status have advantages, such as accelerated permitting procedures, dedicated financial incentives from the NRAs involved and access to the Connecting Europe Facility (CEF). In the period 2014-2020, a total of $€ 5.35$ billion in EU funding was allocated to PCI projects via the CEF.

Second, cross-border cost allocation (CBCA) agreements. Countries used to agree on cross-border investments on the assumption that they would each pay for assets in their ter- 
ritories. If they both benefited enough to justify these costs, they would agree to go forward with the investment. If one of them had doubts, the project would be cancelled or delayed. The country that was more convinced about the project then had an incentive to compensate the neighbour. In Box 4.1 we illustrate two projects where countries started to do this on a voluntary basis.

With the CBCA process, the TEN-E Regulation mandated ACER to act as a mediator in these kinds of cases. TSOs make a CBCA proposal for PCIs, and if the NRAs cannot agree ACER can intervene. This has happened twice so far, namely the Gas Interconnection PolandLithuania (GILP) in August 2014 and the Lithuanian part of the Electricity Interconnection between Lithuania and Poland (LitPol Link) in April 2015. ACER decided that a case where the default cost allocation clearly results in a net loser, that is, a country that benefits less than the costs it is expected to incur by investing in the assets in its territory, is not a justification for applying for CEF funding. Instead, the other beneficiaries are first asked to compensate the net loser for its loss, and other beneficiaries can even be third countries which do not host any of the assets in their territory but clearly benefit from the projects. Only in the GILP case did ACER allocate costs beyond the hosting countries, according to its principle of compensating net losers. In the case of the LitPol Link, ACER decided not to allocate costs to non-hosting countries because there was no net loser.

Our research provides a more detailed discussion of these cases because we had the pleasure of advising ACER in this process. Note that the allocation of CEF funding by the European Commission remains controversial. The $\mathrm{CBA}$ and $\mathrm{CBCA}$ process tried to reduce the politics, but the impression is that this has only been partly accomplished.

\section{BOX 4.1 TWO EXAMPLES OF INNOVATIVE CBCA PRACTICES}

\section{The Norway-Sweden case}

Norway is divided into five bidding zones because it has structural congestion within the country. In dry years, the energy supply within each bidding zone can be very tight. This is the case in mid-Norway, but the situation worsened in 2005 because of new industrial consumption. The situation became critical in the following dry year. The easiest and quickest solution for Norway was to increase the interconnection capacity between mid-Norway and Sweden (line A on the left-hand side of Figure 4.1). This is a 100-km-long $420 \mathrm{kV} \mathrm{AC}$ line between Nea and Järpströmmen, which was commissioned in 2009. Seventy-five per cent of the assets are in Swedish territory. Line B, the line in Norwegian territory (on the left-hand side of Figure 4.1) was expected to increase the available capacity on line A from 200 to $750 \mathrm{MW}$ so that Sweden would also benefit from the cross-border exchange, but line B was less advanced. Norway therefore agreed to compensate Sweden for line A until line $\mathrm{B}$ was ready.

The compensation incentivized Sweden to speed up the development of line A, and also incentivized Norway to speed up the development of line B. The TSOs involved entered into a formal contract, which was approved by their NRAs. 

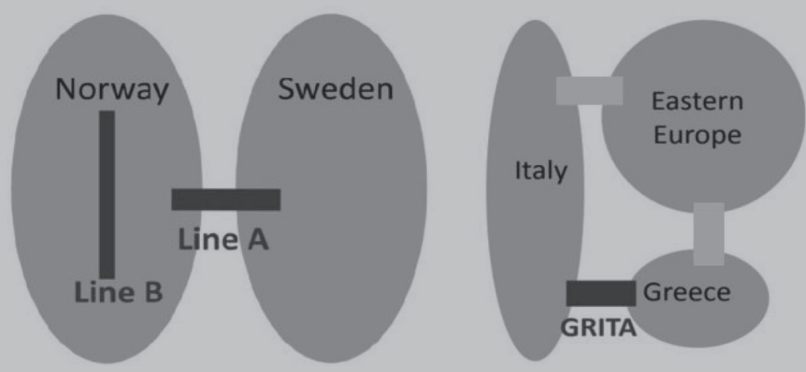

Figure 4.1 The Norway-Sweden case (left) and the Italy-Greece case (right)

\section{The Italy-Greece case}

In 2002, a 500 MW submarine high voltage direct current (HVDC) link between Greece and Italy (GRITA) was commissioned (see the right-hand side of Figure 4.1). Italy paid for and owns 75 per cent of the project and Greece the remaining 25 per cent. The project also received an EU grant, so this CBCA agreement only applied to part of the project costs. The project allows Italy to import cheaper electricity from eastern European countries, like Albania and Turkey, via Greece.

This CBCA showcases innovation, with parties deviating from the common 50:50 cost sharing for an interconnector. It is a typical case in which a transit country (Greece) is compensated to jointly develop a project with its neighbour (Italy).

\subsection{CONCLUSION}

In this chapter on network cost allocation when trade is international, we have answered four questions.

First, who pays for the network? The common practice today for electricity networks is that they are mostly paid for by the network users. There are two types of network tariffs: connection charges and network access charges.

Second, why did national network tariffs start to be harmonized? Transmission network tariffs were somewhat harmonized by Regulation (EU) No 838/2010, which introduced a cap on access charges for generators. Currently, how to apply network tariffs to storage and how to implement the cost-reflectivity principle in distribution network tariffs are open issues.

Third, why was there a move away from transit charges? Transactions do not cause network costs - only flows do; so transit charges were increasing transaction costs rather than charging the users of the grid. Under the inter-TSO compensation scheme, TSOs pay in proportion to the international flows they cause and receive money in proportion to the international flows they host.

Fourth, how to share network investment costs between countries? Each country used to pay for the assets on its territory even if it was not the main beneficiary. Following the TEN-E Regulation, projects can receive project of common interest status. PCIs have several advan- 
tages, including the cross-border cost allocation (CBCA) process in which ACER can mediate in projects to reach a better cost allocation that can help unblock them.

\section{NOTES}

1. In ENTSO-E (2018) there is an overview of transmission tariffs in Europe. This report is updated every year and the facts and figures on transmission tariffs quoted in this chapter come from this report. In Ruester et al. (2012) we provided an academic discussion on transmission tariffs and the possible role of the EU.

2. In Govaerts et al. (2019) we provided a first analysis of the spillover effects of distribution grid tariffs in the internal electricity market. A simplified numerical example is used to give insight into the order of magnitude of the spillovers and the main sensitivities that drive these effects.

3. In Schittekatte et al. (2018) and Schittekatte and Meeus (2020) we discuss why future-proof distribution tariffs need to anticipate the behaviour of households in response to price signals. We also discuss the distributional effects of tariffs by analysing their impact on active versus passive customers. Our colleagues from Comillas and MIT have also done a very interesting analysis on this topic in the 'Utility of the Future' study by the MIT Energy Initiative (2016). In CREG (2018) and Ofgem (2019), the treatment of energy storage for transmission network tariffs is discussed in detail.

4. In ACER (2018b) and ENTSO-E (2019a) there is detailed information on the ITC mechanism. These reports are updated every year with the latest statistics. For more background, refer to ERGEG (2006). Also interesting is academic work on the topic. Olmos and Pérez-Arriaga (2007), Pérez-Arriaga et al. (2002) and Daxhelet and Smeers (2007) analyse the different options that have been considered to implement the ITC scheme. In the conclusions of the 8th and 10th Florence Fora published by the European Commission $(2002,2003)$, the gradual abolishment of transit charges can be observed. The prominence of this issue on the agenda over many years can also be seen from the conclusions of the earlier Florence Fora.

5. The TYNDP is described in ENTSO-E (2019b). The TYNDP is updated every two years. ACER (2018a) reports on the two-yearly PCI list. European Commission (2018) is an example of a press release related to the Connecting Europe Facility (CEF) funding scheme. In Keyaerts et al. (2016) and Meeus et al. (2013) we gave our recommendations for the development of the cost-benefit analysis (CBA) methodology that is used for PCIs in Europe. We also supported ACER in its approach to cross-border cost allocation (CBCA) (ACER, 2015b). In Meeus and He (2014) we made recommendations to ACER when it was given the CBCA mandate. We argued that ACER could only intervene in certain cases to encourage stakeholders to come forward with innovative approaches. The examples shown in Box 4.1 originate from that policy brief. One year later, in Meeus and Keyaerts (2015) we also evaluated the first cases that were treated by the ACER. In Keyaerts and Meeus (2017) we provide case studies on countries that decided to introduce dedicated financial incentives for priority projects. In Bhagwat et al. (2019) we updated our CBA and CBCA analysis with a focus on the implications for meshed offshore transmission networks to support the development of wind power. In Schittekatte et al. (2020) we provide recommendations on how to revise the TEN-E Regulation to be aligned with the objectives of the European Green Deal. Furthermore, for a study on how the incentives of national TSOs are not necessarily aligned with the overall European welfare when deciding about building an interconnector, see the work of Matti Supponen (2011). Finally, for deeper discussions about the implications of the Trans-European Energy Networks (TEN-E) Regulation and its importance, see the book edited by Jean Arnold Vinois (2014). For more details about the two ACER decisions, please consult ACER (2014, 2015a).

\section{REFERENCES}

ACER (2014), 'Decision No 01/2014 of the Agency for the Cooperation of Energy Regulators of 11 August 2014 on the Investment Request including Cross-Border Cost Allocation for Gas Interconnection Poland-Lithuania. Project of Common Interest No 8.5'. 
ACER (2015a), 'Decision No 02/2015 of the Agency for the Cooperation of Energy Regulators of 16 April 2015 on the Investment Request Including Cross-Border Cost Allocation for the Lithuanian Part of the Interconnection between Alytus (LT) and the Lithuanian-Polish Border. Project of Common Interest No 4.5.1'.

ACER (2015b), 'Recommendation No 05/2015 of the Agency for the Cooperation of Energy Regulators of 18 December 2015 on Good Practices for the Treatment of Investment Requests, including CBCA Requests, for Electricity and Gas PCIs'.

ACER (2018a), 'Consolidated Report on the Progress of Electricity and Gas Projects of Common Interest for the Year 2017', published on 10 July 2018.

ACER (2018b), 'ITC Monitoring Report 2018', Report to the European Commission on the Implementation of the ITC Mechanism in 2017, published in October 2018.

Bhagwat, P., T. Schittekatte, L. Lind, N. Keyaerts and L. Meeus (2019), 'D7.4 Economic Framework for a Meshed Offshore Grid', Final Report PROMOTioN.

CREG (2018), 'Besluit tot vaststelling van de tariefmethodologie voor het elektriciteits-transmissienet en voor de elektriciteitsnetten met een transmissiefunctie voor de regulatoire periode 2020-2023' ['Conclusion on the Application of Tariff Methodologies for Electricity Transmission Systems and Electricity Transmission Functions for the Regulatory Period 2020-2023'], Beslissing(Z)1109/10, published on 28 June 2019.

Daxhelet, O. and Y. Smeers (2007), 'The EU regulation on cross-border trade of electricity: A two-stage equilibrium model', European Journal of Operational Research, 181 (3), 1396-412.

ENTSO-E (2018), 'Overview of Transmission Tariffs in Europe: Synthesis 2018', Annual Report, published in May 2018.

ENTSO-E (2019a), 'ITC Transit Losses Data Report 2018', Annual Report, published on 24 September 2019.

ENTSO-E (2019b), 'TYNDP 2018 - Executive Summary', Connecting Europe: Electricity 2025-2030-2040. Final Version after Consultation and ACER Opinion - October 2019.

ERGEG (2006), 'Cover note to ERGEG draft proposal on Guidelines on Inter TSO Compensation', Ref: E06-CBT-09-08a, 10 April 2006.

European Commission (2002), 'European Electricity Regulatory Forum: A significant step forward in completing the internal electricity market', MEMO/02/37. Brussels, 27 February 2002, accessed at https://ec.europa.eu/commission/presscorner/detail/en/MEMO_02_37.

European Commission (2003), 'Florence Forum gets rid of all cross border electricity charges', MEMO/03/153. Brussels, 18 July 2003, accessed at https://ec.europa.eu/commission/presscorner/ detail/en/MEMO_03_153.

European Commission (2018), 'More growth and jobs: EU invests $€ 873$ million in clean energy infrastructure', press release of 25 January 2018, accessed at https://ec.europa.eu/commission/presscorner/ detail/en/IP 18383.

Govaerts, N., K. Bruninx, H. Le Cadre, L. Meeus and E. Delarue (2019), 'Spillover effects of distribution grid tariffs in the internal electricity market: An argument for harmonization?', Energy Economics, 84, accessed at https://doi.org/10.1016/j.eneco.2019.07.019.

Keyaerts, N. and L. Meeus (2017), 'The regulatory experience of Italy and the United States with dedicated incentives for strategic electricity transmission investment', Utilities Policy, 46, 71-80.

Keyaerts, N., T. Schittekatte and L. Meeus (2016), 'Standing still is moving backward for the ABC of the CBA', FSR Policy Brief 2016/08.

Meeus, L. and X. He (2014), 'Guidance for project promoters and regulators for the cross-border cost allocation of projects of common interest', FSR Policy Brief 2014/02.

Meeus, L. and N. Keyaerts (2015), 'First series of cross-border cost allocation decisions for projects of common interest: Main lessons learned', FSR Policy Brief 2015/01.

Meeus, L., N.-H. von der Fehr, I. Azevedo, X. He, L. Olmos and J.-M. Glachant (2013), 'Cost Benefit Analysis in the Context of the Energy Infrastructure Package', Final Report. THINK Project, Topic 10, published in January 2013.

MIT Energy Initiative (2016), 'Utility of the Future: An MIT Energy Initiative Response to an Industry in Transition'. 
Ofgem (2019), 'Open letter on implications of charging reform on electricity storage', Open Letters and Correspondence, published on 24 January 2019.

Olmos, L. and I. Pérez-Arriaga (2007), 'Evaluation of three methods proposed for the computation of inter-TSO payments in the internal electricity market of the European Union', IEEE Transactions on Power Systems, 22 (4), 1507-22.

Pérez-Arriaga, I., L. Olmos and F. J. Rubio (2002), 'Report on Cost Components of Cross Border Exchanges of Electricity', Final Report. Prepared for the Directorate-General for Energy and Transport/European Commission, published in November 2002.

Ruester, S., C. von Hirschhausen, C. Marcantonini, X. He, J. Egerer and J. M. Glachant (2012), 'EU Involvement in Electricity and Natural Gas Transmission Grid Tarification', Final Report. THINK Project, Topic 6, published in January 2012.

Schittekatte, T. and L. Meeus (2020), 'Least-cost distribution network tariff design in theory and practice', Energy Journal, 41 (5), 97-133.

Schittekatte, T., I. Momber and L. Meeus (2018), 'Future-proof tariff design: Recovering sunk grid costs in a world where consumers are pushing back', Energy Economics, 70, 484-98.

Schittekatte, T., A. Pototschnig, L. Meeus, T. Jamasb and M. Llorca (2020), 'Making the TEN-E regulation compatible with the Green Deal: Eligibility, selection, and cost allocation for PCIs', FSR Policy Brief 2020/27.

Supponen, M. (2011), 'Influence of National and Company Interests on European Electricity Transmission Investments', Aalto University Publication Series Doctoral Dissertations, 77/2011.

Vinois, J. A. (ed.) (2014), EU Energy Law Volume VIII - The Energy Infrastructure Policy of the European Union, Deventer, Netherlands and Leuven, Belgium: Claeys \& Casteels. 


\section{A.1 ANNEX: CONGESTION RENT UNDER MARKET COUPLING: A NUMERICAL EXAMPLE}

Suppose that the day-ahead market auction for a certain hour results in a price in zone A of $€ 50 / \mathrm{MWh}$ and a price in zone B of $€ 60 / \mathrm{MWh}$. The satisfied demand in zone A is $100 \mathrm{MWh}$, that in zone $\mathrm{B}$ is $150 \mathrm{MWh}$ and $50 \mathrm{MW}$ of transmission rights are used to trade between the two zones in that hour. In this case, electricity flows from the low-price zone (A) to the high-price zone (B). There is a price difference, which means that the transmission rights have been fully utilized but they were not enough to create a single price zone. The rights therefore have a value and congestion rent is collected, as is illustrated in Table 4A.1.

Table 4A.1 A numerical example of congestion rent calculation

\begin{tabular}{|c|c|c|c|c|c|}
\hline & Price & Demand & Generation & Demand expense & Generation income \\
\hline Zone A & $€ 50 / \mathrm{MWh}$ & $100 \mathrm{MWh}$ & $\begin{array}{l}150 \mathrm{MWh} \\
\text { (demand zone } \mathrm{A}+ \\
\text { interconnector) }\end{array}$ & $€ 5000$ & $€ 7500$ \\
\hline \multirow[t]{2}{*}{ Zone B } & $€ 60 / \mathrm{MWh}$ & $150 \mathrm{MWh}$ & $\begin{array}{l}100 \mathrm{MWh} \\
\text { (demand zone B } \\
\text { - interconnector) }\end{array}$ & $€ 9000$ & $€ 6000$ \\
\hline & & & & $€ 14000$ & $€ 13500$ \\
\hline
\end{tabular}

The total income for generation over the two zones is $€ 13500$ while the total amount spent by demand equals $€ 14000$. The difference between the two is the congestion rent of $€ 500$, equalling the price differential between the two zones $(€ 10 / \mathrm{MWh})$ multiplied by the capacity of the line $(50 \mathrm{MW})$. This congestion rent is transferred to the TSO(s) owning the interconnector. There are strict rules around the use of congestion rent in the EU. Congestion rent should be used to invest in the network; only if the revenues cannot be used efficiently for investments can they be used to lower the national transmission network tariffs. 


\section{A.2 ANNEX: REGULATORY GUIDE}

\section{Table 4A.2 Regulatory guide}

Section of this chapter, topic and relevant regulation

\section{Section 4.1}

TSOs collect congestion revenues, which can cover part of their costs, and thus they can reduce the need to collect money through network tariffs.

\section{Section 4.2}

Caps on G-charges were introduced in Regulation (EU) No 838/2010. The development of guidelines for the harmonization of transmission tariffs was first described in Regulation (EC) No 1228/2003 in the Second Energy Package.

Regulation (EU) 2019/943 and network charges for storage.

Regulation (EU) 2019/943 mandates ACER to come up with best practice reports on transmission and distribution network tariffs.
Relevant article

Relevant article

Regulation (EC) No 714/2009 states in Art. 16(6) that any revenue resulting from the allocation of interconnection shall be used for guaranteeing the actual availability of the allocated capacity and/or maintaining or increasing interconnection capacities through network investment, in particular in new interconnectors. The article continues by stating that 'if the revenues cannot be efficiently used for these [the two above-mentioned purposes], they may be used, subject to approval by the regulatory authorities of the Member States concerned, up to a maximum amount to be decided by those regulatory authorities, as income to be taken into account by the regulatory authorities when approving the methodology for calculating network tariffs and/or fixing network tariffs.'

In Art. 8(3) of Regulation (EC) No 1228/2003 it is stated that, where appropriate, the Commission shall adopt and amend guidelines that determine appropriate rules leading to a progressive harmonization of the underlying principles for the setting of charges applied to producers and consumers (load) under national tariff systems. Regulation (EU) No 838/2010 contains in its Annex part B 'Guidelines for a Common Regulatory Approach to Transmission Charging' in which the caps on G-charges are specified.

Art. 18(1) states that network charges shall not discriminate either positively or negatively against energy storage.

Art. 18(9) states that 'By 5 October 2019 in order to mitigate the risk of market fragmentation ACER shall provide a best practice report on transmission and distribution tariff methodologies while taking account of national specificities.' Furthermore, the article lists several dimensions of network tariffs that were to be addressed, among which are time and location differentiation. It also states that ACER shall update the best practice report at least once every two years. Art. 18(10) adds that 'Regulatory authorities shall duly take the best practice report into consideration when fixing or approving transmission tariffs and distribution tariffs or their methodologies in accordance with Article 59 of Directive (EU) 2019/944.'Art. 59 of Directive (EU) $2019 / 944$ lists the duties and powers of the regulatory authorities. 


Section of this chapter, topic and relevant
regulation

Regulation (EU) 2019/943 states that these tariffs should become more cost-reflective, which can include locational and time-of-use signals.

\section{Section 4.3}

Transit charges were finally abolished in 2004 .

As with G-charges in the previous section, the ITC mechanism was already part of Regulation (EC) No 1228/2003 and was further formalized in Regulation (EU) No 838/2010.

\section{Section 4.4}

Following Regulation (EC) No 714/2009, TSOs make national transmission investment plans. These are consolidated into the so-called Ten-Year Network Development Plan (TYNDP). Regulation (EU) No 347/2013, better known as the Trans-European Energy Networks (TEN-E) Regulation, introduced a process through which some of these projects could become projects of common interest (PCIs).

The PCI list also includes third-party projects. Third-party projects can be merchant projects that have followed an exemption process or regulated projects from countries that allow third parties to compete with TSOs to develop such projects.

The PCI list is updated every two years and contains a selection of electricity transmission lines, gas and oil pipelines, gas and electricity storage projects, electricity smart grids, and carbon dioxide transport infrastructure.
Art. 18(7) states that 'Distribution tariffs shall be cost-reflective taking into account the use of the distribution network by system users including active customers. Distribution tariffs may contain network connection capacity elements and may be differentiated based on system users' consumption or generation profiles. Where Member States have implemented the deployment of smart metering systems, regulatory authorities shall consider time-differentiated network tariffs when fixing or approving transmission tariffs and distribution tariffs or their methodologies in accordance with Article 59 of (EU) 2019/944 and, where appropriate, time-differentiated network tariffs may be introduced to reflect the use of the network, in a transparent, cost efficient and foreseeable way for the final customer.'

Regulation (EC) No 1228/2003, which entered into force on 1 July 2004, formalized the abolishment of transit charges in Art. 4(5) by stating that "there shall be no specific network charge on individual transactions for declared transits of electricity.'

In Art. 8(2) of Regulation (EC) No 1228/2003 it is stated that, where appropriate, the Commission shall adopt and amend guidelines that shall specify the details of the ITC mechanism. Regulation (EU) No 838/2010 contains in its Annex part A 'Guidelines on the Inter-Transmission System Operator Compensation Mechanism.'

Art. 8(3.b) states that ENTSO-E shall adopt 'a non-binding Community-wide ten-year network development plan, including a European generation adequacy outlook, every two years.'

Art. 2 defines a PCI as 'a project necessary to implement the energy infrastructure priority corridors and areas set out in Annex I and which is part of the Union list of projects of common interest referred to in Article 3.' Art. 3 sets out how the Union list of PCIs will be made up. The Commission is empowered to adopt delegated acts that establish the Union list of PCIs. The Commission ensures that the Union list is established on the basis of the regional lists adopted by the decision-making bodies of the Groups. There are 12 regional groups listed in Annex I.

The definition of project promoters in Art. 2(6) of Regulation (EU) No $347 / 2013$ clarifies that a project promoter can not only be a TSO, DSO or other operator but also an investor developing a project of common interest.

Art. 3 of Regulation (EU) No 347/2013 states that the Commission shall ensure that the Union PCI list is established every two years. Annex II of this regulation sets out the energy infrastructure categories which are eligible as PCIs. 


\begin{tabular}{l} 
Section of this chapter, topic and relevant \\
regulation \\
\hline Regulation (EU) No $347 / 2013$ states that to \\
obtain PCI status projects need to conduct \\
a cost-benefit analysis (CBA) following \\
methodology designed by ENTSO-E with \\
supervision by ACER.
\end{tabular}

PCIs can then be ranked based on their CBA and be selected via a process that is set out in the TEN-E Regulation.
Relevant article

Annex III.2(1) setting out the process for establishing regional lists states that 'for projects having reached a sufficient degree of maturity, a project-specific cost-benefit analysis in accordance with Articles 21 and 22 based on the methodologies developed by the ENTSO for electricity or the ENTSO for gas pursuant to Article 11' will be conducted. Art. 4(2) states that all 'the potential overall benefits of the project, assessed according to the respective specific criteria in paragraph 2, outweigh its costs, including in the longer term.' Art. 4(2) lists specific criteria that apply to projects of common interest depending on the specific energy infrastructure categories.

Art. 11(1) states that ENTSO-E (and ENTSOG - European Network of Transmission System Operators for Gas) shall publish and submit to the Member States, the Commission and the Agency their respective methodologies, including on network and market modelling, for a harmonized energy system-wide cost-benefit analysis at Union level for PCIs. Annex V sets out the principles to be satisfied by the methodology for a harmonized energy system-wide cost-benefit analysis for projects of common interest. Art. 11(2) specifies that within three months of the day of receipt of the methodologies, ACER shall provide an opinion to the Member States and the Commission on the methodologies and publish it.

Annex III.2(11) of Regulation (EU) No 347/2013 setting out the process for establishing regional lists states that 'The Group shall meet to examine and rank the proposed projects taking into account the assessment of the regulators, or the assessment of the Commission for oil and carbon dioxide transport projects.' Annex III.2(14) continues with 'If, based on the regional lists received, and after having taken into account the Agency opinion, the total number of proposed projects of common interest on the Union list would exceed a manageable number, the Commission shall consider, after having consulted each Group concerned, not to include in the Union list projects that were ranked lowest by the Group concerned according to the ranking established pursuant to Article 4(4).'

Art. 4(4) of Regulation (EU) No 347/2013 states that 'in order to facilitate the assessing of all projects that could be eligible as PCIs and that could be included in a regional list, each Group shall assess each project's contribution to the implementation of the same priority corridor or area in a transparent and objective manner. Each Group shall determine its assessment method on the basis of the aggregated contribution to the criteria referred to in paragraph 2; this assessment shall lead to a ranking of projects for internal use of the Group.' Art. 4(4) continues with four additional criteria to which each Group shall give due consideration when assessing projects. 


\begin{tabular}{l} 
Section of this chapter, topic and relevant \\
regulation \\
\hline Projects with PCI status have advantages, such \\
as accelerated permitting procedures, dedicated \\
financial incentives from the NRAs involved, \\
and access to the Connecting Europe Facility \\
$(\mathrm{CEF})$.
\end{tabular}

In the CBCA process, the TEN-E Regulation mandates ACER to act as a mediator in these kinds of cases. TSOs make a CBCA proposal for PCIs, and if the NRAs cannot agree, ACER can intervene.
Relevant article

Chapter III of Regulation (EU) No 347/2013 (Arts. 7-10) describes the permit-granting and public participation procedure for PCIs. Chapter IV (Arts. 11-13) describes their regulatory treatment. Lastly, Chapter V (Arts. 14-16) specifies the financing. Art. 14 describes in more detail the eligibility criteria for Union financial assistance for projects. Recital 42 states that 'Projects of common interest in the fields of electricity, gas and carbon dioxide should be eligible to receive Union financial assistance for studies and, under certain conditions, for works as soon as such funding becomes available under the relevant Regulation on a Connecting Europe Facility in the form of grants or in the form of innovative financial instruments ... A three-step logic applies to investments in projects of common interest. First, the market should have the priority to invest. Second, if investments are not made by the market, regulatory solutions should be explored, if necessary the relevant regulatory framework should be adjusted, and the correct application of the relevant regulatory framework should be ensured. Third, where the first two steps are not sufficient to deliver the necessary investments in projects of common interest, Union financial assistance could be granted if the project of common interest fulfils the applicable eligibility criteria.'

Art. 12(6) of Regulation (EU) No 347/2013 states that 'Where the national regulatory authorities concerned have not reached an agreement on the investment request within six months of the date on which the request was received by the last of the national regulatory authorities concerned, they shall inform the Agency without delay. In this case or upon a joint request from the national regulatory authorities concerned, the decision on the investment request including cross-border cost allocation referred to in paragraph 3 as well as the way the cost of the investments are reflected in the tariffs shall be taken by the Agency within three months of the date of referral to the Agency.' Paragraph 3(c) states that the investment request shall be accompanied by a substantiated proposal for cross-border cost allocation if the project promoters agree. 